\title{
Scale and Scope Economies in the Canadian Property and Casualty Insurance Industry
}

\author{
by Jean Marc Suret*
}

\begin{abstract}
This study investigates scale and scope economies in the Canadian property/casualty insurance. Use of the translog cost function allows the estimation of a U-shaped cost curve and of cost elasticities that vary with the size of the insurance company. The model is estimated on a sample of 180 companies over the period 1986 to 1988, and considers four outputs: property, automobile, civil liability, and other types of insurance. The factors of production are labour, rentals, and capital, but the cost of the latter is taken as a constant.

Using data for the years 1986 to 1988 , we show that there exists significant economies of scale for insurance compnanies with assets between $\$ 40$ and $\$ 100$ million. However, the evidence in favour of the existence of economies of scale for smaller and larger firms are limited to one year in each case.

We do not observe systematic evidence of significant cost complementarities between insurance products, nor do we note significant economies of scope. No cost complementarities exist between the two main product lines of property/casualty and automobile. Furthermore, there is some evidence of diseconomies of scope. Diversification economies can only be obtained with liability and other product lines.

Our evidence of slight economies of scale and no economies of scope is compatible with observation that many insurance companies in Canada are small and undiversified.

\section{Introduction}

Because the regulation of the financial sector in Canada is currently under modification, the cost structure of the Canadian insurance industry is a timely research topic. As deregulation would strongly affect the insurance market structure, it is of particular interest to determine if this market appears to be a natural monopoly. If scale and scope economies

* Université Laval, Canada. The author wishes to acknowledge helpful comments from participants at the 1989 International Meetings of the French Finance Association and at the 1990 Productivity and Performance workshop held in Paris. Suggestions from G. Skogh and from H. Chrisman and D. Moffet were particularly helpful, but any remaining errors are the responsibility of the author. Valuable rescarch assistance was provided by E. Cormicr, M. Desnoyers, I. Goulet, M. Laberge and I. Morgat. The author would also like to thank H.H. Chrisman for editorial assistance with the English text. Financial support for this research was provided by La Chaire en Assurance de l'Université Laval.
\end{abstract}


exist, established firms would have a cost advantage as compared to smaller, undiversified, and newly-entering firms. If the decision to enter the market is not reversible without cost, such a market will not be contestable.

As noted by Bernstein and Geehan (1988), there is a need for more evidence on the structure of the production functions of life and property/casualty insurance services. In fact, little research has been done, except for some studies estimating measures of scale economies (and these studies often used incorrect output measures). There is virtually no evidence on the issues of scope economies and productivity growth.

The objective of this study is to improve our knowledge of the cost structure in the property/casualty insurance sector. Furthermore, we will attempt to solve the main problems of previous studics. Thesc problcms are:

1) the utilization of a single-product framework;

2) the measurement of output in the insurance industry;

3) the assumption of restrictive functional forms to represent the production technology;

4) the failure to assess the robustness of various measures of the presence of scale and scope economies;

5) the failure to compute standard errors of the estimates of the parameters that characterise the cost function.

This study relies on the methodological framework developed by Mester (1987) in the savings and loan industry. With respect to the first problem described above, we consider the multiproduct nature of the insurance company by using the theory developed by Baumol, Panzar, and Willig (1982).

We resolve the second problem mentioned above by using two different measures of output, premium income and claims. This permits us to check if the premium income measure of size used in earlier studies produces downward-biased estimates of economies of scale (Skogh: 1982).

This study uses a multiproduct translogarithmic cost function to address the third problem mentioned above. To the best of our knowledge, it is the first time that this type of function has been used in the property/casualty insurance sector.

To assess the robustness of our results and resolve the fourth problem, we replicate our study over each of three years form 1986 to 1988 . We also evaluate the effect of the epsilon value used to replace null values in the data set when a logarithmic function is estimated.

Finally, standard errors are calculated for the main rcsults, using Fuller's (1962) method to estimate the reliability of quantities derived from empirical production functions. This allows us to cvaluate the significance level of coefficients on the variables representing the presence of scale and scope economies.

The first section of this paper discusses briefly several characteristics of economies of production, and summarizes previous studies on cost functions in the insurance industry. The second section presents the models and the estimation procedures. The data and the estimation problems encountered are presented and discussed in the third section, while the last section presents our results. 


\section{Economies of production}

\section{I. Scale and scope economies: concepts and definitions ${ }^{1}$}

For a single product firm, overall economies of scale are present at a production level $y$ if the total production cost of a firm increases less rapidly than its entire output. More formally, the degree of scale economies at $y$ is:

$$
S=C(y) / y C^{\prime}(y)=A C(y) / C^{\prime}(y)=(\text { average cost }) /(\text { marginal cost }) .
$$

Returns to scale are increasing, constant, or decreasing as $S$ is greater than, equal to, or less than unity.

In the multiproduct situation, the degree of scale economies defined over the entire product set at $y$ is given by:

$$
S_{i}(y)=C(y) / \sum_{i=1}^{n} y_{i} C_{i}(y)
$$

where $C_{i}(y) \equiv \partial C(y) / \partial\left(y_{i}\right)$.

Returns to scale are increasing, constant, or decreasing as $S(y)$ in greater than, equal to, or less than unity. This concept of returns to scale relies on a proportional increase in all outputs. Specific economies of scale can also be calculated in the case where the quantities of a subset $T$ of the $N$ different outputs increase, holding other outputs constant.

But a multiproduct firm can also modify the relative proportions of the $N$ outputs. There is also a possibility that cost savings may result from the simultaneous production of different outputs by a single firm, as contrasted to the production of each output in isolation by its own specialized firm. These are economies resulting from the scope of the firm's operation (BPW, p. 71). The degree of economies of scope (which measure the economies of joint production) at $\mathrm{y}$ relative to product set $T$ is given by:

$$
S C_{T}(y)=\left[C\left(y_{T}\right)+C\left(y_{N-T}\right)-C(y)\right] / C(y)
$$

where $y_{T}$ is the vector with a zero component instead of $y_{i}$ for all $i^{9} T$, and $y_{N-T}$ is the vector with a zero component in place of $y_{i}$ for all $i \in T$. Thus, the degree of economies of scope represents the relative increase in cost that would result from the division of the production of $y$ into product lines $T$ and $N-T$.

BPW (1982, p. 75) show that a sufficient condition for a multiproduct cost function to exhibit overall economies of scope at $y^{*}$ is that the cost function must exhibit weak cost complementarities, between each output pair, at all $y$ up to $y^{*}$. That is, $\partial^{2} C(y) / \partial y_{i} \partial y_{j} \leq$ $0, i \neq j$. The cost complementarities imply that the marginal cost of producing any one product decreases with the increase in the quantities of all other products.

1 The main parts of the definition are taken from Baumol, Panzar and Willig (1982) (BPW). 


\subsection{Economies of production in the insurance industry ${ }^{2}$}

Up to now, studics of the cost functions of companics in the insurance industry have been cssentially concerned with cconomics of scalc. In the propcrty/casualty scctor, past research has reported conflicting results in every country in which empirical tests have been undertaken.

In the USA, Allen (1974) found incrcasing returns to scale which disappeared at premium volumes of $\$ 60$ million. Joskow (1973) found returns to scale to be weak or noncxistent except for mutual automobile insurance companies. Hammond, Melander, and Shilling (1967) found incrcasing returns to scalc which disappearcd at premium volumes of $\$ 300$ million . Johnson, Flanigan, and Weisbart (1982) observed dccreasing returns to scale for small and incdium-sized insurers. Howcver, increasing returns to scale were notcd for large insurers with earned premiums in exccss of $\$ 250$ million in 1976. Cho (1988) addressed the issue of possible scale cconomies in workcrs' compcnsation insurance. Statistically significant scale cconomies were present for acquisition, field supervision, and collection expenses. Only weak evidencc of size efficiency was noted for losscs, loss adjustment expenses, and general expenses.

In France, Rosa (1974) observed scale economies for premium volumes between 100 and 1000 million francs. Outreville (1987) found increasing returns to scale, while Dubois (1988) observed constant returns to scale. Skogh (1982), using claims as the measure of output, detected economies of scale in the Swedish property/casualty insurance sector in 1977. Like Skogh, Doherty (1981) used claims as the measure of output in Canada to find evidence in favour of significant size efficiency. Although Outreville and Proulx (1984) noticed significant size efficiency in Canada as well, they also found that economies of scale seemed to disappear after the numerous mergers observed in this sector between 1978 and 1981 .

No definitive conclusions can be drawn from these studies. Mester (1987) ${ }^{3}$ reports that most of the previous empirical cost studies have proxied the multiple outputs either by creating a composite commodity, by choosing one of the firm's outputs to represent all its outputs, or by treating the firm as a collection of separate production functions. ${ }^{4}$ Treating a vector of outputs as a single composite commodity implies holding constant the proportions of the various outputs. Only changes in outputs which vary by a homogeneous percentage can be considered. Furthermore, relative marginal costs of any two outputs are forced to be independent of input prices, and thus the cost function is separable in output. When scparate cost functions are estimated for each output, it is assumed that the marginal cost of producing one output is independent of that of the another outputs. One could crroncously conclude that scale cconomies exist only when cost complementarities are present. Since prior studies do not scparate the issucs of economies of scale and cconomies of scope, their conclusions are not definitive on this point.

2 For a complete review of previous research in this area, see Pestiau and Pirard (1990), Bernstein and Geehan (1988) and Finsinger and Pauly (1986). Clark (1988) summarizes studies of economies of scale and scope in deposit financial institutions.

${ }^{3}$ Mester's conclusions are based on an analysìs of empirical studies of banking firms, but her conclusions could also apply to empirical studies on the insurance sector's cost functions.

4 To the best of our knowledge, there is only one study treating both scale and scope economies in the insurance sector; however, it focuses on the life insurance industry (Kellner and Mathewson: 1983). 
Another important limitation of previous studies concerns the measurement of output. Premium income is generally used to represent output, which can underestimate real economies of scale. The problems associated with the measurement of output of property/ casualty insurance companies are discussed in the third section.

\section{Estimation procedures}

\subsection{The cost function}

Following Mester (1987), a translogarithmic cost function is estimated in this research. This flexible function imposes only restrictions consistent with the existence of a dual relationship between the cost and transformation functions. There were no restrictions on the first and second order derivatives. Production functions estimated in previous research on economies of scale in the insurance industry have often been of either the Cobb-Douglas or the constant elasticity of substitution forms. These production functions are not consistent with economies or diseconomies of scale and scope over all relevant output ranges, and results are thus biased from the outset when inflexible functional forms are adopted. The translog function permits the evaluation of the characteristics of the cost function, such as its separability or if it takes the Cobb-Douglas form. Furthermore, fewer parameters must be estimated when using the translog function as compared to other flexible forms (Caves, Christiansen and Tretheway, 1980). The main problem with the translog function is that cost must equal zero when the output level is equal to zero. However, the flexibility of this functional form has made it the currently most popular choice in multiproduct cost studies.

For $n$ products $\left(y_{i}\right)$ and $m$ inputs $\left(w_{i}\right)$, the translog function may be written:

$$
\begin{aligned}
& \ln C=\alpha_{\mathrm{o}}+\sum_{i=l}^{n} \alpha_{i} \ln Y_{i}+\sum_{j=l}^{m} \beta_{j} \ln w_{j} \\
& +1 / 2 \sum_{i=l}^{n} \sum_{j=l}^{b} \sigma_{i j} \ln y_{i} \ln y_{j} \\
& +1 / 2 \sum_{j=l}^{m} \sum_{k=l}^{m} \delta_{k l} \ln w_{j} \ln w_{k} \\
& +1 / 2 \sum_{i=l}^{n} \sum_{j=l}^{m} \tau_{i j} \ln y_{i} \ln w_{j}
\end{aligned}
$$

From Shepherd's Lemma, the derived demand functions are found by differentiating the translog cost function with respect to the input prices. The input share equations are given by:

$$
\begin{aligned}
& S_{j}=\partial \ln C / \partial \ln w_{j} \\
& \mathrm{~S}_{\mathrm{j}}=\beta_{j}+\sum_{i=l}^{n} \delta_{i j} \ln y_{i}+\sum_{k=l}^{m} \beta_{j k} \ln w_{k}
\end{aligned}
$$


The translog cost function must be homogeneous of degree one in input prices. This implies the following parameter restrictions: ${ }^{5}$

$$
\sum_{j} \beta_{j}=1 \quad \sum_{i} \delta_{i j}=\sum_{j} \beta_{j k}=\sum_{k} \beta_{j k}=0
$$

Furthermore, the second order coefficients must be symmetric. This implies

$$
\sigma_{i j}=\sigma_{j i} \quad \delta_{j k}=\delta_{k j} \quad \alpha_{i j}=\alpha_{j i}
$$

In our study, variables are:

$y_{1}$ : Property insurance

$y_{2}$ : Automobile insurance

$y_{3}:$ Liability insurancc

$w_{\jmath}$ : Unit cost of salaries

$w_{2}$ : Unit rental cost

A dummy variable (FORM) is included to control for the organizational form, stock $v s$ mutual.

We estimated the model without the input share equation, because we did not have sufficient data to estimate $S_{j}$. Omitting the input share equation is a common practice in current multiproduct cost studies (Gilligan, Smirlock, and Marshall: 1984; Goldstein, McNulty, and Verbrugge: 1987). Murray and White (1983) obtain similar results when including or excluding the input share equations.

\subsection{Degrees of scale and scope economies}

The estimation of the translog function is only the first step; the second step is to calculate the degrees of scale economies and scope economies present. We accomplished this by using the definitions of Panzar and Willig (1977) and BPW (1982), and the estimation techniques described by Murray and White (1983) and Kim (1987).

Panzar and Willig (1977) demonstrate that a local measure of overall economies of scale $(S L)$ for a multiproduct firm is the scale elasticity:

$$
S L=C(Y, W) / \sum_{i} y_{i} M C_{i}=1 / \Sigma \frac{\partial \ln C}{\partial \ln y_{i}}=1 / \Sigma \alpha_{i}
$$

where $M C$ is the marginal cost with respect of the ith output.

The cost elasticity of the $i$ th output can be obtained from the translog function by:

$$
\gamma_{i}=\alpha_{i}+\sum_{j} \sigma_{i j} \ln y_{i}+\sum_{k} \delta_{i k} \ln w_{k}
$$

At the point estimate, if $y_{i}=w_{k}=1$, overall economies of scale are reduced to:

$$
S L=\left(\Sigma_{i} \alpha_{i}\right)^{-1}
$$

This simplification requires a standardization of the data before estimating the model. Muray and White, as well as Kim, use this tranformation.

BPW (1982) define product-specific scale economies $S L_{i}$ for product $i$ as:

$$
S L_{i}=\frac{I C_{i}(Y, W)}{Y_{i} M C_{i}(Y, W)}=\frac{I C_{i} / C}{\gamma_{i}}
$$

\footnotetext{
${ }^{5}$ See Christensen, Jorgenson and Lau (1973).
} 
where $I C_{i}(Y, W)$ is the incremental cost of the $i$ th product, defined as the difference in cost incurred by the firm in producing the mean level of product $i$ as opposed to zero production of product $i$, while the quantities of the other produts are held constant.

Kim (1986) noted that the estimation of $S L_{i}$ requires the calculation of the cost function at the zero output level. For most firms, this requires a long extrapolation of the cost function far outside the range of the sample output levels over which the cost functions is estimated. He proposed to use 10 percent of the mean output level as a reference point. ${ }^{6}$ Product-specific scale economies can then be derived from the translog coefficients as:

$$
S L_{i}=\frac{\exp \left(\alpha_{o}\right)-\exp \left(\alpha_{o}+\alpha_{i} \ln \epsilon+1 / 2 \sigma_{i i}(\ln \epsilon)^{2}\right)}{\alpha_{i} \exp \left(\alpha_{o}\right)}
$$

where $\epsilon_{i}=0.0001,0.001,0.01,0.1$ or 0.15 .

The concept of product-specific scale economies can be extended to a subset of products. The degree of scale economies specific to the products $y_{i}$ and $y_{i}$ can be obtained at the point of approximation of the translog cost function by:

$$
S L_{i j}=\frac{\exp \left(\alpha_{o}\right)-\exp \left(\alpha_{o}+\alpha_{i} \ln \in+\alpha_{i} \ln \epsilon+1 / 2 \sigma_{i i}(\ln \in)^{2}+1 / 2 \sigma_{i j}(\ln \in)^{2}\right)}{\exp \left(\alpha_{o}\right)\left(\alpha_{i}+\alpha_{i}\right)}
$$

We have seen that the degree of overall economies of scope $(S C)$ at $y$ relative to product set $T$ is given by:

$$
S C_{T}=\left(C\left(y_{T}\right)-C\left(y_{N-T}\right)-C(y)\right) / C(y)
$$

In the three-output case, $S C$ can be derived from the coefficient of the translog function as:

$$
\begin{aligned}
S C & =\left[\exp \left(\alpha_{o}+\alpha_{2} \ln \epsilon+\alpha_{3} \ln \epsilon+1 / 2 \sigma_{22}(\ln \epsilon)^{2}+1 / 2 \sigma_{33}(\ln \epsilon)^{2}\right)\right. \\
& +\exp \left(\alpha_{o}+\alpha_{1} \ln \epsilon+\alpha_{3} \ln \epsilon+1 / 2 \sigma_{11}(\ln \epsilon)^{2}+1 / 2 \sigma_{33}(\ln \epsilon)^{2}\right) \\
& +\exp \left(\alpha_{o}+\alpha_{1} \ln \epsilon+\alpha_{2} \ln \epsilon+1 / 2 \sigma_{11}(\ln \epsilon)^{2}+1 / 2 \sigma_{22}(\ln \epsilon)^{2}\right) \\
& \left.-\exp \left(\alpha_{o}\right)\right] / \exp \left(\alpha_{o}\right)
\end{aligned}
$$

Because cost complementarity among products is a sufficient condition for a multiproduct cost function to exhibit overall economics of scope, we also calculated these cost complementarities. As already mentioned, the cost complementarities imply that the marginal cost of producing any one product decreases with increases in the quantity of all other products.

From the translog function, cost complementarities can be detected by calculating cross-marginal elasticities at the approximation point by:

$$
C=\frac{\partial \ln M C_{i}}{Z \ln y_{i}}=\frac{l}{\alpha_{i}}\left(\delta_{i j}+\alpha_{i}\left(\alpha_{i}-\Delta_{i j}\right)\right)
$$

6 It can be shown that Kim's results are highly sensitive to the choice of this reference point. For example, the product-specific economies of scale cocfficient is 1.007 when the reference points is 0.10 , but is becomes .935 when this point rises to 0.15 . The extremely large confidence intervals surrounding the computed value are noted by Clark (1988). We used 5 different reference points (from 0.0001 to $0.15)$ to assess the robustness or our results. 
where $\Delta_{i j}=1$ for $i=j$ and $\Delta_{i j}=0$ for $\neq i j$. A negative cross-marginal elasticity implies a cost complementarity between two products. Following Murray and White (1983), we used an approximate test of this condition, which is:

$$
\alpha_{i} \alpha_{j}+\sigma_{i j}<0
$$

Output combinations satisfying (12) benefit from cost complementarities.

Finally, we calculated product-specific scope economies. As mentioned above, such economies exist when the joint production of an output with the existing combination of other outputs is cheaper than its production separate from the other outputs. At the point of approximation of the translog cost function, $S C_{i}$ are given by:

$$
\begin{aligned}
& S C_{i}=\left[\exp \left(\alpha_{o}+\sum_{j \neq i} \alpha_{j} \ln \epsilon+1 / 2 \sum_{j \neq i} \sum \sigma j j(\ln \epsilon)^{2}\right)\right. \\
& \left.+\exp \left(\alpha_{o}+\alpha_{i} \ln \epsilon+1 / 2 \sigma_{i i}(\ln \epsilon)^{2}\right)-\exp \left(\alpha_{o}\right)\right] / \exp \left(\alpha_{o}\right) \text {. }
\end{aligned}
$$

The estimation of a confidence interval around these statistics representing the degrees of $S L$ and $S C$ follows in the next section.

\subsection{Confidence intervals}

A weakness of previous studies is the failure to compute standard errors of the estimates of the parameters characterising the cost function. This calculation is complex, because it is necessary to estimate the standard deviations of statistics which are non-linear functions of the estimated parameters. Fuller (1962) showed that the variance covariance matrix of such variables $\left(Z_{l}, Z_{2} \ldots Z_{n}\right)$ that are functions of the estimated parameters $\left(a_{l}\right.$, $\left.a_{2} \ldots a_{r}\right)$ is given by $D \Sigma D^{\prime}$, where:

$$
D=\left[\begin{array}{llll}
\partial Z_{l} / \partial a_{l} & \partial Z_{l} / \partial a_{2} & \ldots & \partial Z_{l} / \partial a_{r} \\
\vdots & & & \\
\partial Z_{l} / \partial a_{l} & \ldots & & \partial Z_{l} / \partial a_{r}
\end{array}\right]
$$

where the partial derivatives are evaluated at the point estimates of $\left(a_{l} \ldots a_{r}\right)$ and $\Sigma$ is the variance-covariance matrix of the parameters. We used this methodology to calculate the standard deviations and significance levels of our estimated parameters. In this study, $S L$, $S L_{i}, S C, S C_{i} \ldots$ are the $Z_{i}$ and the cost function parameters are the $a_{j}$.

\section{Data and estimation process}

\subsection{The problem of output measurement}

A great deal of controversy and confusion surrounds the nature of the outputs provided by insurance firms (Bernstein and Geehan: 1988). The measure of output most often used in current studies is premium income (Joskow: 1973, Johnson, Flanigan and Weisbart: 1982, Cho: 1988). However, Skogh (1982) showed that this approach involves a serious bias: premium income adequately measures output only under constant returns to scale in a long run competitive equilibrium. As one of the goals of this study is to test for the existence of constant returns to scale, it would be inappropriate to measure output by premium income. Furthermore, Skogh points out an econometric problem which is linked with the measurement of output by premium income. A simultaneity bias results from a positive relationship 
between the explanatory variable, premium income, and the dependant variable, administrative costs. Premium income is composed of claims plus administrative costs; thus, the estimated economies of scale will be less than the true economies if premium income is used as a measure of size. Bernstein and Geehan note that premium income is not a correct measure of output, because it does not capture the risk-pooling nature of insurance.

This study follows Skogh's (1982) recommendation ${ }^{7}$ to use claims as the measure of the volume of output. However, we also computed scale and scope economies indicators using net premium income as the measure of output. A comparison of the two sets of cost function and production economies indicators allows an empirical evaluation of the appropriateness of the two alternative measures of output.

\subsection{Prices of input factors}

Three input factors are considered in this study: they are labour, rentals, and capital. The cost of capital is assumed constant across firms, as it is generally admitted that firms from the same sector belong to the same risk class. Even if they differ by their financial leverage, they should have the same cost of capital since financial leverage should not affect the cost of capital (Miller: 1977).

Wages can fluctuate from one geographic area to another. We thus first determined in which region each sample company appeared to be undertaking most of its operating activity. In a second step, we attributed to each company the average wage cost in the service sector of the area, as published by Statistics Canada.

Rentals, or the depreciation of real estate investment, appears to be an expensive item. We estimated the average rental rate (per square foot) for the main cities in Canada from the annual market study of the real estate firm Royal Lepage. This estimation technique for rental costs has already been used in Gilligan and Smirlock (1984), and in Benston, Hanweck, and Humphrey (1982) in the banking sector.

\subsection{Output and cost measurement}

Premium income, claims, and expenses were collected from the Report of the Superintendent of Financial Institutions: Abstract of Property and Casualty Insurance Companies (The Report), for the years 1986 to 1988 .

We considered the three main products of the property casualty insurance industry: automobile, property casualty and liability. These three lines of products represent more than $80 \%$ of insurance industry activity. Other insurance lines were grouped in a residual class to allow for a comprehensive model specification.

All canadian insurance companies classified in the property/casualty sector in the Federal Report were included in the sample. Insurance companies that do not operate in one of the main insurance sectors, or which had negative or null expenses, were excluded from the sample. We defined three subsamples based on the level of total assets. Small firms were those having assets lower than $\$ 40$ million (\$30 million in 1986), large firms

\footnotetext{
${ }^{7}$ However, Cho (1988), in a more recent study, writcs that the use of claims is subject to serious criticism and does not constitute the right measure of output. Insurance product should also include auxiliary services; moreover, the amount of claims paid should be more preferably treated as a cost. He suggests using premium income.
} 
were those having assets in excess of $\$ 100$ million ( $\$ 80$ million in 1986), and medium-sized firms were between these two limits. Each group contains from 50 to 70 companies, depending on the year.

The main variables were defined as follows. Net claims include adjustment expenses. Property insurance (claims and premiums) includes personal and commercial insurance lines, and automobile insurance includes personal, liability, and other automobile insurance products. Total costs are composed of commissions and overhead expenses. When premium income is used as the measure of output, total costs include claims and relative expenses, and net premium income (i. e. direct premium income plus reinsurance assumed minus reinsurance added) is used as the measure of output.

When one line of insurance is not offered by a firm, a null value appears in the data set. ${ }^{8}$ As $\ln (0)$ is not defined, we replaced each null value by 0.1 and also tested the model using different values. Since null values appear essentially in the liability and the other insurance products categories, grouping these two lines together would be another way to solve this problem. However, we do not observe any significant effects of these various specifications on the coefficient values and significance levels. Nevertheless, the replacement of the liability and the other insurance products categories with a combined category entails important consequences in terms of the measurement of scale and scope economies.

\subsection{Estimation process}

\section{Step one: Estimation of the cost function}

Equation 1 is linear in its unknown parameter and thus OLS estimation can be used. The translog cost function was therefore estimated by using the REG procedure of SAS software, for the total sample and for each subsample, and for each of the years 1986, 1987, and 1988. The presence of influential variables, multicollinearity, and heteroskedasticity were tested by using the methodologies presented in Besley, Kuh, and Welch (1980). Prior normalization of the variables seems to be crucial in order to obtain a correct specification of the model. Without this transformation, variance inflation tests reveal a strong multicollinearity problem.

\section{Step two: Estimation of the degrees of scale and scope economies}

Using equations (5), (7), (8), (10), (12) and (13), we calculated the degrees of scale and scope economies by product, by product pair, and by product group, for each year and for each group of firms. These equations require an approximation of the zero production level and, as mentioned above, calculations were replicated with the null values $\epsilon$ of 0.0001 , $0.001,0.01,0.1$, and 0.15 . As shown in Kim (1986), the scale and scope coefficients seem to be highly sensitive to the value of $\epsilon$. Furthermore, for a given $\epsilon$, the choice of $\epsilon_{0}$ also affects the value and the sign of the coefficients representing scale and scope economies. In fact, the sign and the magnitude of the coefficients representing scale and scope economies appear to be essentially a function of the value used to replace the null values in the data set when estimating the equations (5) to (13).

\footnotetext{
${ }^{8}$ The value used in place of $\theta$ in the data set for estimating the cost function is denoted $\epsilon_{0}$. $\epsilon$ is the value used to approximate zero production in equations (5) through (12).
} 
This can explain in part the conflicting results offered by previous studies. As a result. it is extremely important to define condifence intervals around the indicators representing the presence of scale and scope economies.

\section{Step three: Calculation of confidence interval}

Fuller's (1962) approach was used to calculate the standard deviation of the main parameter estimates. These standard errors allow us to test the following hypotheses:

- The overall scale economies coefficient is significantly different from 1.

- The overal scope economies coefficient is significantly different from 0 .

- Significant cost complementarities exist between products $i$ and $j$.

These tests were replicated with different replacement values for null production. The conclusions drawn from these statistical tests do not seem to be affected by the choice of $\epsilon_{0}$ and $\epsilon$, even through this choice affects the value of the parameters. No definitive conclusion can be drawn, relative to the presence of scale and scope economies when a translogarithmic cost function is used, without performing statistical tests on the degrees of scale and scope economies represented by the estimation of the model.

\section{Results}

\subsection{Estimation of the cost function}

Table 1 shows the coefficients of the cost function estimated for 1986 using total costs and both measures of output. Since the results are very similar in terms of the signs and significance levels of the coefficients, we can conclude that the choice of the output measure seems to be unimportant to estimate the cost function.

Most of the coefficients are statistically significant and carry their expected sign. The control variable FORM was never significant, so the reported results exclude this variable. The coefficients of the level 1 terms are positive and statistically significant, except for the rental costs. Positive coefficients are as would be expected as they indicate a positive relationship between cost and output. The insignificant coefficient associated with the second input (rental cost) could be due to a less intensive use of this input when the unit rental cost is high.

The coefficients of the squard terms are positive and statistically significant. This implies that no linear form could be adapted to the description of the functional cost relationship. As economies of scale should not be constant, we use groups of firms of the remainder of this study.

The coefficients of the cross-product terms are generally significantly negative. This is a necessary (but not sufficient) condition for cost complementarities, which in turn is a sufficient condition for scope economies. The significance level of these terms implies that the cost process cannot be represented by separate cost functions. 
Table 1

Coefficients of the translogarithmic cost functions, by measure of output in 1986

Claims as output

Coefficients
T value

$-12.287$

10.016

9.436

2.670

4.328

5.670

$-0.143$

8.809

$-2.328$

$-0.322$

$-1.260$

6.402

$-1.467$

$-2.478$

2.650

$-0.321$

3.203

$-1.516$

$-0.289$

1.442

1.079

$-2.962$

$-1.122$

0.554

1.539

$-1.158$

$-1.770$

$-0.980$

Premium income as output

Coefficients

$\mathrm{T}$ value

\section{$-0.437913^{*}$}

$0.401407^{*}$

$-8.830$

$0.383908^{*}$

12.644

$0.091417^{*}$

17.606

$0.064343^{*}$

4.577

$0.992985^{*}$

6.303

0.007015

9.430

$0.064334^{*}$

0.067

$-0.044823^{*}$

7.419

$-0.012534^{*}$

$-0.010584^{*}$

$-4.418$

$0.037391^{*}$

$-1.276$

$-0.016097^{*}$

9.597

$-0.013516^{*}$

$-2.271$

$0.012699^{*}$

$-3.008$

$-0.003007$

3.189

$0.008113^{*}$

$-0.645$

$-1.700385$

3.514

$-0.310092^{*}$

$-0.609$

2.010478

$-0.956$

$-0.184548$

0.673

0.020597

$-0.382$

0.105347

0.245

-0.043546 *

0.268

0.176069

$-0.731$

$-0.055893^{*}$

0.547

$-0.060114$

$-0.029508$

$-1.376$

$-0.481675$

$0.011482^{*}$

$-0.140$

0.404

n:

R-square:

Adj. R-sqaure:
161

0.9227

0.9091

\section{8 \\ 0.9696 \\ 0.9648}

$\mathrm{Y} 1=$ property

$\mathrm{Y} 2$ = automobile

$\mathrm{Y} 4=$ other

$\mathrm{W} 1=$ salaries

$\mathrm{Y} 3$ = liability

$\mathrm{W} 2=$ rental cost

* significant at the $5 \%$ level

Table 2 completes the description of the cost function for 1986, with a separate estimation of the function for each group of firms. The signs on the coefficients appear to be generally consistent with previous aggrcgated results, and are similar across groups. The 
Table 2

Coefficients of the translogarithmic cost function, by size group

Small companies Medium companies Large companies

Coefficients $T$ values Coefficients $T$ values Coefficients $T$ values

\begin{tabular}{|c|c|c|c|c|c|c|}
\hline Intercept & -1.658077 & -5.520 & -0.999158 & -4.158 & $-(0.363521$ & -2.222 \\
\hline $\ln (Y 1)$ & $0.444255^{*}$ & 5.214 & $0.365737^{*}$ & 4.364 & $-0.633920^{*}$ & 9.415 \\
\hline $\ln (Y 2)$ & 0.100751 & 1.229 & (0.358795* & 3.196 & $0.361573^{*}$ & 5.169 \\
\hline $\ln (Y 3)$ & 0.010959 & 0.202 & 0.038929 & 0.548 & 0.023409 & 0.399 \\
\hline $\ln (Y 4)$ & $0.131841^{*}$ & 4.080 & 0.011039 & 0.260 & 0.076316 & 1.637 \\
\hline $\ln (\mathrm{Wl})$ & 0.586607 & 1.408 & $0.960759 *$ & 2.402 & $2.322359^{*}$ & 4.119 \\
\hline $\ln (\mathrm{W} 2)$ & 0.413393 & 0.992 & 0.039241 & 0.098 & $-1.322359^{*}$ & -2.345 \\
\hline $\ln (Y 1)^{*} \ln (Y 1)$ & $0.052887^{*}$ & 2.972 & $0.049629^{*}$ & 3.864 & $0.051145^{*}$ & 3.514 \\
\hline $\ln (Y 1)^{*} \ln (Y 2)$ & -0.012245 & -1.437 & 0.023288 & 0.618 & -0.016759 & -0.478 \\
\hline $\ln (\mathrm{Y} 1)^{*} \ln (\mathrm{Y} 3)$ & -0.017727 & -1.488 & $0.0(04281$ & 0.207 & -0.064624 & -1.147 \\
\hline $\ln (Y 1)^{*} \ln (Y 4)$ & $-0.023958^{*}$ & -2.141 & 0.000328 & -0.033 & $-0.042306^{*}$ & -1.263 \\
\hline $\ln (Y 2)^{*} \ln (Y 2)$ & 0.008166 & 0.746 & 0.005271 & -0.156 & 0.029547 & 5.643 \\
\hline $\ln (\mathrm{Y} 2)^{*} \ln (\mathrm{Y} 3)$ & 0.016099 & 0.955 & -0.001300 & 0.037 & -0.064059 & -1.472 \\
\hline $\ln (\mathrm{Y} 2)^{*} \ln (\mathrm{Y} 4)$ & -0.002539 & -0.231 & -0.013109 & -0.396 & 0.013370 & 0.362 \\
\hline $\ln (Y 3)^{*} \ln (Y 3)$ & 0.014412 & 1.108 & 0.008628 & 0.661 & 0.016522 & 1.114 \\
\hline $\ln (Y 3)^{*} \ln (Y 4)$ & -0.013936 & -1.527 & -0.006761 & -0.795 & 0.002280 & 0.08 \\
\hline $\ln (\mathrm{Y} 4)^{*} \ln (\mathrm{Y} 4)$ & $0.031962^{*}$ & 2.773 & 0.005401 & (). 509 & -0.001048 & -0.189 \\
\hline $\ln (\mathrm{W} 1)^{*} \ln (\mathrm{W} 1)$ & -4.719056 & -0.429 & 4.143749 & 0.322 & -10.746294 & -1.544 \\
\hline $\ln (W 2) * \ln (W 2)$ & 1.186406 & 0.889 & 1.285232 & 0.925 & -3.828883 & -1.720 \\
\hline $\ln (W 1)^{*} \ln (W 2)$ & 3.532651 & 0.298 & -5.428981 & -0.387 & 14.575177 & 2.313 \\
\hline $\ln (\mathrm{Y} 1)^{*} \ln (\mathrm{W} 1)$ & 0.184363 & 0.254 & 0.679038 & 0.549 & 2.375461 & 1.176 \\
\hline $\ln (\mathrm{Y} 1)^{*} \ln (\mathrm{W} 2)$ & -0.248953 & -1.891 & 0.078140 & -0.481 & 0.122443 & 0.595 \\
\hline $\ln (\mathrm{Y} 2)^{*} \ln (\mathrm{W} 1)$ & 0.151311 & 0.195 & -0.172467 & 0.013 & -1.021917 & -0.602 \\
\hline $\ln (\mathrm{Y} 2)^{*} \ln (\mathrm{W} 2)$ & -0.191333 & -1.146 & 0.140094 & 0.616 & 0.160139 & 0.776 \\
\hline $\ln (\mathrm{Y} 3)^{*} \ln (\mathrm{W} 1)$ & 0.810499 & 0.935 & -1.260370 & -0.997 & -1.698505 & -0.831 \\
\hline $\ln (\mathrm{Y} 3)^{*} \ln (\mathrm{W} 2)$ & $-0.257863^{*}$ & -2.398 & 0.124765 & 0.982 & -0.025051 & -0.107 \\
\hline $\ln (\mathrm{Y} 4)^{*} \ln (\mathrm{W} 1)$ & -0.280346 & -0.493 & 0.363841 & 0.424 & -0.026885 & -0.043 \\
\hline $\ln (\mathrm{Y} 4)^{*} \ln (\mathrm{W} 2)$ & 0.167678 & -1.509 & -0.141695 & -1.087 & 0.114416 & 1.466 \\
\hline $\mathrm{n}:$ & 46 & & \multicolumn{2}{|l|}{54} & 59 & \\
\hline R-square: & 0.9221 & & \multicolumn{2}{|l|}{0.8698} & 0.9273 & \\
\hline Adj. R-sqaure: & 0.8372 & & \multicolumn{2}{|l|}{0.7656} & 0.8774 & \\
\hline \multicolumn{3}{|l|}{$\mathrm{Yl}=$ property } & \multicolumn{4}{|l|}{$\mathrm{Y} 4=$ other } \\
\hline \multicolumn{3}{|l|}{$\mathrm{Y} 2$ = automobile } & \multicolumn{4}{|c|}{$\mathrm{W} 1=$ salaries } \\
\hline \multicolumn{3}{|l|}{$\mathrm{Y} 3$ = liability } & \multicolumn{4}{|c|}{$\mathrm{W} 2=$ rental cost } \\
\hline
\end{tabular}

significance levels are lower because of the limited size of the sample, given the great number of coefficients to be estimated.

We obtained similar results for 1987 and 1988. These results are not reported here, since the presence of scale and scope economies is the main interest in this study. 
Table 3

Economies of scale and economies of scope by size group with claims as a measure of output and standard errors of estimation 1986

$\begin{array}{lll}\text { Small } & \text { Medium } & \text { Large } \\ \text { Companies } & \text { Companies } & \text { Companies }\end{array}$

Overall scale economies (standard error of estimation)

Product-specific scalc economies: $S L i$

1
2
3
4

1

4
1.143

(0.152)

1.291

$(0.113)^{*}$

0.931

(0.076)

$\begin{array}{lll}1.380 & 1.391 & 1.158 \\ 1.526 & 1.584 & 1.465 \\ 1.763 & 1.659 & 0.429 \\ 1.758 & 1.000 & 2.142\end{array}$

Dual-product scale economies

\section{1 vs 2 \\ 1 vs 3 \\ 1 vs 4 \\ 2 vs 3 \\ 2 vs 4 \\ 3 vs 4}

Overall scope economies

(standard error of estimation)

Dual-product scope economies

$$
\begin{aligned}
& 1 \text { vs } 2,3 \text { and } 4 \\
& 2 \text { vs } 1,3 \text { and } 4 \\
& 3 \text { vs } 1,2 \text { and } 4 \\
& 4 \text { vs } 1,2 \text { and } 3
\end{aligned}
$$

$(0.272)$

$-0.169$

$-0.152$

0.054

0.067

Cost complementarities (if negative)

(standard error of estimation)
1 vs 2
1 vs 3
1 vs 4
2 vs 3
2 vs 4
3 vs 4

$\begin{array}{ccc}0.117^{*} & 0.155^{*} & 0.212^{*} \\ (0.048) & (0.036) & (0.023) \\ 0.032 & 0.019 & -0.050 \\ (0.025) & (0.050) & (0.022) \\ 0.024 & 0.004 & 0.006 \\ (0.021) & (0.040) & (0.018) \\ 0.017 & 0.015 & -0.056^{*} \\ (0.048) & (0.046) & (0.017) \\ 0.010 & -0.009 & -0.041 \\ (0.024) & (0.027) & (0.013) \\ 0.005 & -0.006 & -0.004 \\ (0.009) & (0.028)^{*} & (0.010)\end{array}$

\subsection{7}

1.335

1.364

1.499

1.550

1.499

0.076

$(0.138)$

0.879

1.121

1.095

1.388

1.385

1.724

$-0.146$

(0.153)

$\begin{array}{rr}-0.109 & -0.344^{*} \\ -0.114 & -0.309^{*} \\ 0.145 & 0.095 \\ 0.187 & -0.040\end{array}$




\section{Table 4}

Economies of scale and economies of scope by size group with claims as a measure of output and standard errors of estimation 1987

Overall scale economies (standard error of estimation)

Product-specific scale economies: $S L i$

\section{Small Companies}
1.786

$(0.106)^{*}$

2.386

1.634

2.472

1.957

1.457

2.328

2.100

1.618

1.535

2.004

0.305

(0.219)

(standard error of estimation)

Dual-product scope economies

$$
1 \text { vs } 2,3 \text { and } 4
$$

2 vs 1,3 and 4

3 vs 1,2 and 4

4 vs 1,2 and 3
$-0.002$

$-0.016$

0.220

0.167
Medium

Companies

1.270

$(0.095)^{*}$
Large

Companies

0.976

$(0.072)$

1.158

1.508

1.822

1.780

1.489

1.326

2.602

7.912

1.017

0.932

1.083

1.119

1.396

1.364

1.317

1.276

1.429

1.830

1.703

0.072

$-0.108$

$(0.171)$

(0.101)

$-0.256^{*}$

$-0.228^{*}$

0.018

0.182

0.289

$-0.066$

Cost complementarities (if negative)

(standard error of estimation)

$\begin{array}{lccc}1 \text { vs } 2 & 0.194^{*} & 0.079 & 0.051 \\ & (0.033) & (0.053) & (0.042) \\ 1 \text { vs } 3 & 0.129 & 0.057 & 0.075 \\ & (0.027)^{*} & (0.046) & (0.039) \\ 1 \text { vs } 4 & 0.095 & -0.036 & -0.018 \\ & (0.025)^{*} & (0.039) & (0.029) \\ 2 \text { vs 3 } & -0.087 & -0.005 & 0.007^{*} \\ & (0.024)^{*} & (0.036) & (0.026) \\ 2 \text { vs } 4 & -0.035 & 0.018 & 0.025 \\ & (0.019) & (0.031) & (0.014) \\ 3 \text { vs } 4 & -0.058 & 0.009 & 0.012 \\ & (0.021)^{*} & (0.017)^{*} & (0.009)\end{array}$


Table 5

Economies of scale and economies of scope by size group with claims as a measure of output and standard errors of estimation 1988

Small

Companies

Overall scale economies (standard error of estimation)

1.318

$(0.145)^{*}$

Product-specific scale economies: $S L i$
1.347

2.207

1.658

1.872

1.185

1.266

1.289

1.846

1.921

1.674

0.109

$(0.068)$

(standard error of estimation)

Dual-product scope economies

Dual-product scale economies

$$
\begin{aligned}
& 1 \text { vs } 3 \\
& 1 \text { vs } 4 \\
& 2 \text { vs } 3 \\
& 2 \text { vs } 4 \\
& 3 \text { vs } 4
\end{aligned}
$$

Medium

Companies

1.473

$(0.109)^{*}$
Large

Companies

1.279

$(0.088)^{*}$
$-0.126$

$-0.078$

0.108

0.117
1.330

1.279

2.304

$-5.498$

1.167

1.381

1.320

2.582

2.256

2.554

0.023

(0.156)

1.521

1.812

1.315

2.005
1.239

1.368

1.383

1.570

1.594

1.619

0.171

(0.147)
2 vs 1,3 and 4

4 vs 1,2 and 3
$-0.170$

$-0.171$

0.265

0.178

Cost complementarities (if negative)

(standard error of estimation)

$\begin{array}{lccc}1 \text { vs } 2 & 0.128^{*} & 0.255^{*} & 0.134^{*} \\ 1 \text { vs } 3 & (0.028) & (0.059) & (0.021) \\ & 0.012 & -0.007 & -0.050 \\ 1 \text { vs } 4 & (0.019)^{*} & (0.041) & (0.027) \\ & -0.009 & 0.024 & 0.042 \\ 2 \text { vs } 3 & (0.019) & (0.031) & (0.024) \\ & 0.034 & -0.081 & -0.003 \\ 2 \text { vs } 4 & (0.014)^{*} & (0.039)^{*} & (0.017) \\ & -0.009 & -0.015 & -0.001 \\ 3 \text { vs } 4 & (0.014) & (0.032) & (0.021) \\ & 0.002 & -0.025 & -0.010 \\ & (0.003) & (0.016)^{*} & (0.015)\end{array}$




\subsection{Economies of scale}

The two first lines of tables 3 to 5 show us the degree of overall scale economies, as calculated with equation (5), and the standard error of estimation of this coefficient. These results are presented for each year and for each group, along with significance tests. To calculate the significance of the estimated coefficients, $t$ values at $\alpha=0.05$ for 25 to 40 degrecs of freedom were used. The degrees of freedom were given by the number of observations (anywhere from 51 to 66) minus the number of cstimated paramcters (26).

We observe statistically significant scale economies for each year for mcdium-sized companies. Scale economies are present for small firms in only 1987 and for large ones in only 1988. For these groups, no definitive conclusion can be drawn from these results because of the instability of the overall scale economies cocfficient. We can conclude that there exist significant overall economies of scale only for mcdium-sized insurance companies.

Positive coefficients on the degrees of product-specific and dual-product economies of scale indicate that increasing onc activity can generally be profitable for the firm. This is true only if this operation does not affect the other product lines. These coefficients are similar for each year.

\subsection{Economies of scope}

Tables 3 to 5 indicates that there are no overall economies of scope in the Canadian property/casualty insurance industry. The large size of the standard errors of estimation seems to explain the lack of significant scope economies. These large standard errors could not be avoided since it was necessary to estimate a very large number of parameters. The coefficient is negative in 1986 and 1987 for large firms. This could imply that large undiversified firms hold a cost advantage relative to multiproduct companies.

The cost complementarities tests confirm the absence of scope economies. Of particular interest is the cost complementarity between products 1 and 2 (property and automobile). This coefficient is positive and statistically significant for the three groups in 1986 and 1988 . It becomes insignificant, although positive, in 1987 for medium and large firms. Such a result can be observed if the insurance market is characterised by economies of specialization. Single-product insurance companies appear to perform better than dual-product companies. Significant cost complementarities could be observed for large firms only in 1986 and for medium and small firms only in 1987. In each case, adding the third line of insurance, liability, leads to cost complementarities. The automatic link betwcen property and liability insurance (particularly for housing insurance) could explain this result.

Dual-product scope economies are generally negative for the two main product lines. This indicates diseconomies of scope between property and automobile insurance. This is particularly true for large firms, for which the coefficients representing dual-product scope economies are significantly negative in 1986 and 1987.

\subsection{Economies of production and the choice of output measure}

Table 6 is analogous to Tablc 4, but the cost function is estimatcd with net premium income as the measure of output in Table 6 . Total cost includes operating expenses, claims, and adjustment expenses. The results are similar to those presented in Table 4, except for the overall scope economies coefficient for large firms, which is significantly positive. This 
Table 6

Economies of scale and economies of scope by size group with net premium income as the measure of output and standard errors of estimation

1987

Overall scale economies

(standard error of estimation)

Product-specific scale economies : $S L i$
Small

Companies

1.294

(0.261)
Medium

Companies

(0.217)

Large

Companies

1.022

(0.035)

$\begin{array}{lrr}1.417 & 1.396 & 1.354 \\ 2.000 & 1.612 & 1.270 \\ 1.813 & 1.307 & -0.981 \\ 2.054 & 1.884 & 1.906\end{array}$

Dual-product scale economies

I vs 2
1 vs 3
1 vs 4
2 vs 3
2 vs 4
3 vs 4

Overall scope economies

(standard error of estimation)

Dual-product scope economies

$$
\begin{array}{r}
1.302 \\
1.124 \\
1.578 \\
1.662 \\
-1.283 \\
2.132 \\
-0.183 \\
(0.497)
\end{array}
$$

$-0.194$

$-0.000$

$-0.192$

0.268

Cost complementarities (if negative)

(standard error of estimation)

$\begin{array}{cccc}\text { I vs } 2 & 0.189 & 0.088 & 0.091 \\ 1 \text { vs } 3 & (0.067) & (0.050) & (0.035) \\ & 0.103 & 0.089 & -0.086 \\ 1 \text { vs } 4 & (0.158) & (0.064) & (0.031) \\ & -0.031 & 0.025 & 0.078 \\ 2 \text { vs } 3 & (0.150) & (0.023) & (0.019) \\ & -0.010 & -0.052 & -0.010 \\ 2 \text { vs } 4 & (0.065) & (0.042) & (0.028) \\ & -0.061 & -0.046 & 0.000 \\ 3 \text { vs } 4 & (0.038) & (0.047) & (0.015) \\ & 0.018 & -10.027 & -0.023 \\ & (0.055) & (0.016) & (0.012)\end{array}$

0.957

1.035

1.282

1.001

1.208

0.474

0.210

(0.084)

(0.229)

$-0.110$

$-0.112$

0.263

0.087

$\begin{array}{rr}0.005 & -0.110 \\ -0.004 & -0.112 \\ 0.191 & 0.263 \\ 0.217 & 0.087\end{array}$


result is puzzling because the dual-product scope economies coefficients are negative for the two main product lines, and we observe only one significantly negative cost complementarity between lines 1 and 4 . We obtain similar conclusions by comparing the two sets of results for 1986 and 1988 .

One could conclude from these results that, when analyzing the cost function's characteristics, the correct evaluation of the significance level of the various measures of scale and scope economies is more relevant than the choice of the output measure.

\section{Conslusion}

The main objective of this research is the measure of economies of scope and economies of scale in the Canadian property/casualty insurance industry. Using data for the years 1986 to 1988 , we show that there exists significant economies of scale for insurance companies with assets between $\$ 40$ and $\$ 100$ million. However, the evidence in favour of the existence of economies of scale for smaller and larger firms are limited to one year in each case.

We do not observe systematic evidence of significant cost complementarities between insurance products, nor do we note significant economies of scope. No cost complementarities exist between the two main product lines of property/casualty and automobile. Furthermore, there is some evidence of diseconomies of scope. Diversification economies can only be obtained with liability and other product lines.

Our study also has some important implications on a methodological level. In fact, we observe that, when analyzing the cost function's characteristics, the correct evaluation of the significance level of the various measures of scale and scope economies is more relevant than the choice of the input measure.

The lack of significance tests for the existence of scale and scope economies in previous studies preclude any comparison of our empirical results with those in the past research. 


\section{REFERENCES}

ALLEN. R. F. (1974). "Cross-sectional estimates of cost economies in stock property-liability companies". The Review of Economics and Statistics $56(100-103)$.

BAUMOL, W. J. and BRAUNSTEIN. Y. L. (1977). "Empirical study of scalc economies and production complementary: The case of journal publication". Journal of Political Economy 85. No. 5.

BAUMOL. W. J.. PANZAR. J. C. and WILLIG. R. D. (1982). "Contestable markets and the theory of industry structure", New York. Harcourt Brace Jovanowitch. Inc.

BENSTON. G. J., HANWECK. G. and HUMPHREY. D. (1982). "Scales economies in banking: A restructuring and reassessment". Journal of Money. Credit and Banking 14. (435-456).

BESLEY. D. A.. KUH. E. and WELSCH. R. E. (1980). "Regressions diagnostics", Wiley ed.

BROWN. R. S. CAVES. D. W. and CHRISTENSEN. L. R. (1979). “Modelling the structure of cost and production for multiproduct firms". Southern Economic Journal, (256-278).

CAVES. W.. CHRISTENSEN. L. R. and TRETHEWAY. M. (1980) "Flexible cost functions for multiproduct firms". Review of Economics and Statistics 62. (474-481).

CHO. D. (1988), "Some evidence of scale economies in worker's compensation insurance". The Journal of Risk and Insurance 55. No. 2. (324-330).

CHRISTENSEN. L. R.. JORGENSON. D. W. and LAU. L. J. (1973), “'Transcendental logarithmic production function frontiers". The Review of Economics and Statistics 55. (29-45).

CLARK. J. A. (1988), "Economies of scale and scope at depository financial institutions: A review of the literature". Economic Review 73. No. 8. (16-33).

COLENUTT. D. W. (1977), "Economies of scale in the United Kingdom ordinary-life industry". Applied Economics 9. (219-225).

CUMMINS. J. D. and VANDERHEI. J. (1979). “A note on the relative efficiency of property liability insurance distribution systems". The Bell Journal of Economics 10. (709-719).

CUMMINS. J. D. (1977). "Economies of scale in independant insurance agencies". Journal of Risk and Insurance 44. pp.

DENNY. M. and FUSS. M. A., "The use of approximation analysis to test for separability and existence of consistent aggregates". American Economic Review 67. June 1977. 4(1)4-418.

DIEWERT. W. E. and WALES. J. J. "Flexible functional forms and global curvature conditions". Econometrica 55. 1987. (43-68).

DOHERTY. N. A. (1981). "The measurement of output and economies of scale in property-liability insurance". Journal of Risk and Insurance, 48. (390-402).

DUBOIS. P. "Estimation d'une fonction de coût hédonique: compagnies d'assurance IARD". Cinquièmes journées de Micro-Economie Appliquée. Toulouse. 9-10 juin 1988.

FULLER. W. A. "Estimating the reliability of quantities derived from empirical production fonctions", Journal of Furm Economics 44. February 1962. (82-99).

GEEHAN. R. (1977), "Returns to scale in the life insurance industry". The Bell Journal of Economics 8. $(181-191)$.

GILLIGAN. T. W. and SMIRLOCK. M. L. (1984). "An empirical study of join production and scale conomies in commercial banking". Journal of Banking and Finance 8. (67-77).

HAMMOND. J. D.. MELANDER. E. R. and SHILLING, N. (1971). "Economies of scale in the property and liability insurance industry". The Journal of Risk and Insurance 38 No. 2. (181-191).

HARRINGTON. S. (1982). “Operation expenses and economies of scale for agency and non-agency life insurers: further evidence". Journal of Risk and Insurance. (229-253).

HIRSHORN. R. and GEEHAN. R. (1977). "Measuring the real output of the life insurance industry". Review of Economics and Statistics 49. (211-219). 
JOHNSON, J. E., FLANIGAN, G. B. and WEISBART, S. N. (1982), "Return to scale in the property and liability insurance industry", The Journal of Risk and Insurance, (18-46).

JOSKOW, P. W. (1973), "Cartels, competition and regulation in the property-liability insurance industry", The Bell Journal of Economics 4, (375-427).

KELLNER, S. and MATHEWSON, G. F. (1983), "Entry, size distribution, scale and scope economies in the life insurance industry", Journal of Business 56, (25-44).

KIM, M., "Banking technology and the existence of a consistent output aggregate", Journal of Monetary Economics 18, 1986, (181-195).

KIM, M. Y. (1986), "Economies of scale and scope in multiproduct financial institutions: Further evidence from credit unions", Journal of Money, Credit and Banking 18, (220-226).

MESTER, L. J. (1987), "A multiproduct cost study of savings and loans", Journal of Finance 42, $(423-445)$.

MILLER, M. (1977), "Debt and taxes", Journal of Finance, (261-275).

MURRAY, J. D. and WHITE, R. W. (1983), "Economies of scale and economies of scope in multiproduct financial institutions: A study of British Columbia credit unions", Journal of Finance, 38 , (887-901).

O'BRIEN, C. D. (1989), "Measuring the output of life assurance companies", Paper presented to the Staple Inn Actuarial Society, (5th December).

OUTREVILLE, J. F. (1987), "L'Assurance en France: essais d'analyse macro-économique”, Etudes et Dossiers No. 113, Association Internationale pour l'étude de l'économie de l'assurance", 1987.

OUTREVILlE, J. F. and PROULX, C. (1985), "Fusions et économies de dimension sur le marchė des assurances générales au Québec", Actualité Economique 61, No. 3, (350-360).

PANZAR, J. C. and WILLIG, R. O. (1977), "Economies of scale in multi-output production", Quarterly Journal of Economics $91,(481-493)$.

PANZAR, J. C. and WILliG, R. O. (1981), "Economies of Scope", American Economic Review 71 , $(262-272)$

PESTIEAU, P. and PIRARD, Ch., "L'entreprise d'assurance: économies d'échelle et performance", Paper presented at the workshop: Productivity and Performance in Insurance, Paris, January 1990.

SHEPHARD, R. S., Cost and Productions Functions, Princeton University Press, Princeton, New Yersey, 1953, 102 pages.

SKOGH, G. (1982), "Returns to Scale in the Swedish Property-Liability Insurance Industry", The Journal of Risk and Insurance 49, No 2, (218-228).

SKOGH, G. (1986), "The Regulation of the Swedish Insurance Industry", in The Economics of Insurance Regulation, J. Finsinger and V. Pauly Ed., Macmillan Press Ltd, 1986. 